\title{
La justicia como imparcialidad, progreso y perfección
}

\author{
Justice as fairness, progress and perfection \\ Diego Alejandro Otero Angelini \\ Universidad Panamericana, México \\ diego_otero1@hotmail.com
}

\begin{abstract}
Resumen
En el presente artículo analizo la justificación del antiperfeccionismo rawlsiano, presente tanto en Teoría de la Justicia como en Liberalismo Político, con la finalidad de mostrar cómo la justicia como imparcialidad, la concepción de la justicia de Rawls, sufre profundos problemas de estabilidad gracias a esa característica. Como una alternativa a dicho antiperfeccionismo propongo, en una segunda parte, la idea de progreso como perfeccionamiento práctico de John Dewey. Sostengo que un liberalismo perfeccionista de este tipo no atenta contra el pluralismo razonable, como Rawls sostenía, y que es indispensable para poder establecer una sociedad liberal que perdure. Al final muestro, brevemente, cómo podría verse afectado el ámbito del espacio privado una vez que la idea de progreso forma parte de una concepción de la justicia liberal.
\end{abstract}

Palabras clave: liberalismo, perfeccionismo, progreso, política.

\begin{abstract}
In this article I analyze the justification of rawlsian anti-perfectionism, present in both A Theory of Justice and Political Liberalism. My aim is to show how justice as fairness, Rawls's conception of justice, lacks stability because of it. As an alternative to his anti-perfectionism, I propose, in the second part, the idea of progress as practical perfectionism by John Dewey. I argue that a perfectionist liberalism of this kind does not undermine reasonable pluralism as Rawls argued. Also I argue
\end{abstract}

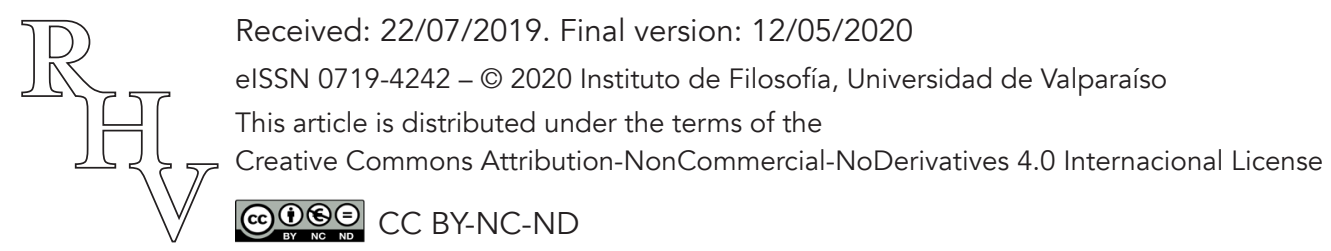


that it is indispensable to establish a liberal society that is stable. In the end, I briefly show how the private sphere could be affected once the idea of progress is part of a conception of liberal justice.

Keywords: liberalism, perfectionism, progress, politics.

\section{Introducción}

Si bien el progreso es un ideal formativo típico, aunque no necesario, de la política liberal norteamericana del siglo XX, su tratamiento intelectual amerita cuidado. Un problema con el concepto del progreso en el pensamiento liberal, como identificó John Rawls, es que supone, en muchos casos, un estado final al que se debe llegar y, por lo mismo, puede legitimar la opresión de ideas morales o religiosas que no compartan dicho ideal dentro de sus ideas del bien. La noción de progreso que defenderé en este artículo está relacionada con la idea de perfección en sentido práctico de John Dewey y no supone un estadio final para justificarse, del mismo modo en que la evolución por selección natural tampoco lo necesita, y por eso defenderé que es compatible con una concepción de la justicia como la justicia como imparcialidad. Sin embargo, Rawls mantiene una concepción de la justicia liberal antiperfeccionista que deja de lado la idea del progreso y su importancia para una sociedad bien ordenada.

¿Por qué el ideal perfeccionista es rechazado por Rawls?, ¿qué problema hay con hablar de los logros de la sociedad en términos de progreso?, ¿es la idea del progreso incompatible con una visión liberal de la justicia? Para Rawls el problema del perfeccionismo, desde Teoría de la Justicia, se encuentra en que, siempre que una sociedad mantenga una idea de perfección que influya u oriente la concepción de la justicia, es parcial respecto de doctrinas comprehensivas que no contemplen la misma idea de perfección como un fin aceptable; en ese sentido es injusta (por ser parcial) con ellas. Asumiendo que fuera imposible mantener una idea de perfección y desarrollo para la sociedad que pueda justificarse en términos de imparcialidad, parecería necesario renunciar a dicho ideal pues su imposición sería inaceptable en la posición original, la situación hipotética diseñada por Rawls para encontrar los términos justos de cooperación social desde la imparcialidad (Rawls 1999, 15-17). La sociedad bien ordenada de Rawls, que existe bajo la condición del pluralismo razonable (Rawls 1999, 63-66), no podría adoptar una concepción de la justicia que discrimina injustamente ideas del bien de la sociedad y, por lo tanto, tendríamos que rechazar las ideas de perfeccionismo y progreso en general.

En el primer apartado de este artículo analizaré el antiperfeccionismo de Rawls en su formulación de la justicia como imparcialidad (presente tanto en Teoría de la Justicia como en Liberalismo Político). De igual modo, analizo los mecanismos que, según Rawls, permiten que la concepción de la justicia sea estable. Concluyo esa primera parte 
mostrando algunos de los que me parecen los problemas centrales de dicha postura. La segunda parte la dedicaré a analizar la posibilidad de plantear la compatibilidad de la justicia como imparcialidad con un cierto ideal de progreso. Para hacer esto mostraré cómo, aunque Rawls afirme que las razones filosóficas son innecesarias para justificar el liberalismo político - lo que afirma explícitamente el Liberalismo Político y, asume, es posible hacerlo incluso desde Teoría de la Justicia (Rawls 2005, XXX)—, existe una idea de ser humano en la tradición liberal, presente también en el pensamiento de Rawls, que permite plantear un tipo de perfeccionismo que no atenta contra el pluralismo razonable. En la última sección procuraré abordar, con brevedad, algunas implicaciones de reconocer el ideal de progreso que propongo, haciendo notar las diferencias en la aplicación de la justicia como imparcialidad en una sociedad bien ordenada; en especial haciendo énfasis en la relevancia de la educación (de los menores de edad), lo que fue uno de los temas centrales del pensamiento de John Dewey, de quien tomo la idea de "perfeccionismo en sentido práctico" desarrollada en el segundo apartado.

\section{Antiperfeccionismo, la justicia como imparcialidad y el problema de la estabilidad}

El antiperfeccionismo rawlsiano asume que ideas del bien distintas, en un estado de imparcialidad y dentro de los límites de razonabilidad, son incomparables. La imposición del velo de la ignorancia, junto con los límites a la motivación en la posición original, obliga a las partes a considerar las distintas ideas del bien de modo imparcial, pues no pueden saber cuál será la que ellas tendrán. Rawls espera que el velo de la ignorancia obligue a las partes que "deciden" sobre la concepción de la justicia a considerar dichas ideas del bien imparcialmente (Rawls 1999, 118-120). Debido a que no hay una idea del bien trascendente que nos sirva como criterio para comparar y juzgar distintas comprensiones del bien, es necesario reconocer que todas son inicialmente igual de aceptables mientras las sostengan personas razonables.

La justicia, como primera virtud social, está encargada primordialmente de la distribución de bienes (Rawls 1999, 3-4). En el caso de la justicia como imparcialidad, su labor es garantizarlos en la medida justa para que los individuos sean capaces de alcanzar la realización de sus ideas del bien (Rawls 1999, 78-81). La justicia como imparcialidad supone que cada idea del bien, suponiendo que sea razonable, es igualmente aceptable bajo un contexto imparcial. Al no desarrollar una idea del bien que ordene cuáles concepciones son aceptables, nos encontramos con la necesidad de aceptarlas todas, generando condiciones materiales y de autorrespeto para que puedan ser perseguidas por los ciudadanos en condiciones de libertad y justa igualdad, siempre y cuando su existencia no represente un riesgo inminente para la existencia de la concepción de la justicia (Rawls 1999, 191192). 
La justicia como imparcialidad, progreso y perfección

Diego Alejandro Otero Angelini

El ejercicio de la tolerancia dentro de la comunidad política está enmarcado por los límites de la conservación del orden y la seguridad. El principio de tolerancia supone que el gobierno no está en condiciones de afirmar qué idea del bien es mejor, por el contrario:

[...] dados los principios de la justicia, el Estado debe ser entendido como la asociación conformada por ciudadanos iguales. No debe preocuparse con doctrinas filosóficas y religiosas, sino regular la búsqueda de los individuos de sus intereses morales y espirituales de acuerdo con los principios con los que ellos mismos estarían de acuerdo en una posición inicial de igualdad [...] el gobierno no tiene ni el derecho ni el deber a hacer lo que él o la mayoría (o quién sea) quiera hacer en cuestiones de moralidad y religión. Su deber está limitado a garantizar las condiciones de igualdad moral y libertad religiosa. (Rawls 1999, 190)

La idea de que el Estado pueda asumir el papel de árbitro sobre qué ideas del bien son correctas es un peligro constante por el cual, en buena medida, vino a existir la tradición liberal (con su búsqueda de la defensa de la privacidad). Rawls formula un argumento sugerente cuando sostiene que "donde la supresión de la libertad está basada en principios teológicos o asuntos de fe, ninguna discusión racional es posible" (Rawls 1999, 90). Así, busca garantizar la estabilidad de la comunidad política mediante los principios de la justicia: en tanto las distintas ideas del bien no contradigan directamente la concepción de la justicia que sería elegida por los individuos en una circunstancia de imparcialidad donde se reconozca su autonomía, deben de ser respetadas y toleradas. Lo que es más, de acuerdo con Rawls el trato tolerante debe ser garantizado incluso con aquellos que son intolerantes siempre que la constitución, y por tanto la estructura básica gobernada por una concepción de la justicia razonable, no corra ningún riesgo: "Cuando la constitución está por sí misma segura, no hay ninguna razón para negar la libertad al intolerante" (Rawls 1999, 192).

Esta tolerancia hacia los intolerantes plantea un posible escenario de inestabilidad para cualquier sociedad liberal. Rawls es consciente de esto y analiza la importancia de la imparcialidad y el impacto en la psicología moral en Teoría de la Justicia, así como la relevancia del consenso traslapado, como mecanismo estabilizador de la sociedad, en el Liberalismo Político (Rawls 2005, 391). Me enfocaré al argumento desarrollado en Teoría de la Justicia pues, considero, el consenso traslapado requiere de este primer paso. El consenso traslapado en Rawls depende de la posibilidad de hacer de la justicia como imparcialidad la opción libremente elegida por todas las doctrinas comprehensivas sin necesidad de intervención del gobierno más allá de la aplicación de la concepción a la estructura básica de la sociedad. Considero que, si puedo mostrar que los argumentos en Teoría de la Justicia no se sostienen por sí, difícilmente podríamos construir el caso por el consenso traslapado con las implicaciones que tiene en Liberalismo Político; como es, por ejemplo, que la concepción no puede ser aceptada por un simple modus vivendi (Rawls 2005, 146). 
Esta idea de tolerancia se encuentra presente en el esfuerzo no fundacionalista del Liberalismo Político. En este texto Rawls pretende presentar la justicia como imparcialidad de modo que pueda ser estable (Rawls 2005, 140-143). Para hacer esta presentación Rawls muestra que puede elaborar una teoría que no dependa de una doctrina comprehensiva particular y, después, realizará una defensa de la estabilidad en función a la psicología moral y el "consenso traslapado". En este artículo me enfocaré, para plantear el problema de la estabilidad, en el tema de la psicología moral, en especial del modo en que fue desarrollado en Teoría de la Justicia; aunque vale la pena aclarar por qué lo haré así. Por un lado, como se verá en el desarrollo del artículo, en especial a partir del siguiente apartado, la idea de hacer una concepción de la justicia que pueda ser no fundacionalista, es decir que no dependa de una idea moral del bien (que yo defenderé que debe de ser una idea moral liberal), me parece inestable.

Dado el alto grado de idealidad que Rawls asume para la sociedad en Liberalismo Político, vaciar la concepción de la justicia de contenido comprehensivo puede ser posible (Rawls 2005, 35-40); sin embargo, en las sociedades reales esta opción no existe. No sólo eso, en la medida en que Rawls busca como garantía de estabilidad el "consenso traslapado" de una concepción de la justicia no defendida en términos morales, implica que cada una de las doctrinas comprehensivas tendrán sus propias razones morales que las llevarán a aceptar la concepción (Rawls 2005, 144-146). El problema con esta propuesta, y por lo que me parece que el centro del análisis debe estar en el tema de la psicología moral, es que Rawls presenta la poco plausible idea de una sociedad en la que todos viven bajo la justicia como imparcialidad, ven los buenos resultados, están convencidos de que funciona y, por lo mismo, sus propias doctrinas comprehensivas elaboran las justificaciones morales necesarias para aceptarla. Esto significa que los ciudadanos no pueden aceptar la concepción de la justicia como parte de un mero modus vivendi; Rawls asume que hay dos cuestiones por las que un consenso traslapado es distinto de un modus vivendi: "primero, el objeto del consenso, la concepción política de la justicia, es en sí una concepción moral. Segundo, se afirma a sí misma en términos morales, es decir, incluye concepciones de la sociedad y los ciudadanos como personas [...]" (Rawls 2005, 147).

¿Por qué es esto un problema? La cuestión que Rawls no responde es: ¿por qué asumiríamos que existen sociedades así? Rawls pone el carro antes de los caballos: dado que la sociedad se gobierna por una concepción de la justicia adecuada, los ciudadanos tendrán un consenso de la concepción de la justicia fundamentado en sus propias doctrinas comprehensivas (que tienen criterios de justificación distintos, en algunos casos incomparables), pero, ¿quién gobernó, si no fueron ciudadanos previamente socializados de acuerdo a los valores de la justicia como imparcialidad, con esa concepción para que los ciudadanos presentes se convencieran de la corrección de la concepción? El problema es que los ciudadanos necesitan, primero, tener una concepción de la justicia, al menos parcial, que arroje los resultados adecuados para entrar en un "círculo virtuoso" en el que la justificación moral compartida genere las condiciones sociales aceptables para todos y 
La justicia como imparcialidad, progreso y perfección

Diego Alejandro Otero Angelini

que, a su vez, reconozcan lo conveniente de dicha concepción. Rawls, con el giro político, hace procedentes críticas como las de Sheldon Wolin, quien, después de plantear como "(L)a garantía de la estabilidad no es, digamos, el aprecio profundo de los ciudadanos por la vida democrática o el patriotismo, sino el consenso traslapado" (Wolin 2016, 270), reconoce como:

Lo que no reconoce la fórmula liberal de, "Derechos Iguales+Libertad=Democracia", es que Americanos Africanos, otras personas de color, Judíos e irlandeses católicos no harán eco a los valores liberales de tolerancia, igualdad y libertad porque sus experiencias históricas tienen un trasfondo distinto del que el optimismo histórico de la sensibilidad liberal permite: un trasfondo por un lado de experiencias de nativismo, esclavitud, antisemitismo y anti catolicismo y, por otro lado, de las categorías "listas para usar" de los derechos iguales para todos más allá de los traumas históricos. (Wolin 2016, 272)

Como se verá a continuación, cuando analice el modo en que Rawls plantea la psicología moral y cómo los individuos aceptan una concepción de la justicia determinada, Rawls parece considerar una especie de generación "natural", casi espontánea, de una socialización adecuada para vivir en una sociedad ordenada por la justicia como imparcialidad. Aun cuando aceptáramos que la socialización puede ocurrir de ese modo natural-espontáneo (y eso no significaría que no podamos socialmente, a través de la educación, orientar la socialización para ordenarnos a una concepción de la justicia determinada), eso no significa que genere condiciones de estabilidad. Por tanto, me parece que el centro del argumento por la estabilidad está en Teoría de la Justicia pues, aun cuando Rawls defiende en la introducción del Liberalismo Político (Rawls 2005, xv) que la distinción entre una doctrina moral y una política de la justicia no está en Teoría, me parece, por razones que se verán en este artículo, que es esa la razón por la que el argumento por la estabilidad está mejor desarrollado ahí. Al final de cuentas, el consenso sobre la concepción de la justicia (independientemente del nivel o tipo de consenso que sea), requiere de una psicología moral bien justificada, lo que está mejor presentado en Teoría.

En Teoría de la Justicia hay dos maneras de explicar por qué Rawls considera que la justicia como imparcialidad sería una concepción estable. Por un lado se encuentra el principio de imparcialidad, que es el que informa los deberes y obligaciones, por otro, está el funcionamiento de nuestra psicología moral, por la que Rawls piensa que los principios terminarían siendo aceptados por los ciudadanos.

Sobre el principio de imparcialidad podemos decir que, de acuerdo con Rawls, supone que las personas están obligadas a hacer lo que les corresponde según las reglas de una institución siempre que hayan aceptado voluntariamente los beneficios de dicho esquema y cumpla con los criterios de justicia (Rawls 1999, 301). Asume que existe un principio moral, derivado de una idea intuitiva, que estipula que "no debemos ganar del esfuerzo cooperativo de otros sin haber hecho lo que nos correspondía con justicia hacer" (Rawls 1999, 301). El principio de imparcialidad sirve como fundamento de las relaciones de jus-

Revista de Humanidades de Valparaíso, 2020, No 15, 21-40

(c) $(9)(9)$ CC BY-NC-ND 
La justicia como imparcialidad, progreso y perfección

Diego Alejandro Otero Angelini

ticia en tanto los miembros participantes reconocen la naturaleza del esfuerzo cooperativo que implica que las partes sólo pueden beneficiarse cuando cooperen con los objetivos comunes.

Una condición necesaria para que el principio de imparcialidad pueda operar es que cada uno de los participantes debe tener confianza en que sus contrapartes lo reconocen y están dispuestas a cumplir con su parte del esfuerzo cooperativo (Rawls 1999, 305). Si pensamos en la posibilidad de que el esfuerzo cooperativo lo lleven a cabo personas intolerantes, con prejuicios, encontramos un primer problema. Cuando una de las partes no piensa que los demás son igualmente dignos, el cumplimiento del principio de imparcialidad se ve seriamente comprometido; del mismo modo, la víctima de discriminación probablemente dude de que su contraparte, el intolerante, esté en disposición de cumplir con el principio. Si la existencia de intolerancia y grupos de odio fuera algo más o menos común en la comunidad política, el cumplimiento de los principios derivados de la posición original, por razón de la imparcialidad, estaría sujeta a una continua negociación que más parecería un perpetuo dilema del prisionero. El principio de imparcialidad requiere, para que podamos considerar su aplicación razonablemente, que las partes cuenten con una moralidad con rasgos democráticos y liberales en la que todos deben pensarse como individuos iguales. Donde las partes no se consideran iguales, no queda claro que puedan compartir la misma noción de mérito.

Este problema es aun más agudo en el Liberalismo Político, con el "giro político" de Rawls, cuando la influencia de la concepción de la justicia en la conformación de la psicología moral de los ciudadanos es dejada de lado, en contraste a la formulación de Teoría de la Justicia. En el Liberalismo Político nos encontramos con ciudadanos que, en el contexto de una teoría ideal, ya poseen una moral liberal; esto es evidente en la caracterización de la cultura de fondo que hace Rawls (Rawls, 2005, 443-444). Una teoría que presuponga ciudadanos moralmente liberales, por momentos, parece ser una que no se refiere a las posibilidades concretas de la realidad.

Si nos imaginamos estar en la posición original, en donde todos los individuos están cubiertos por el velo de la ignorancia y se consideran iguales en tanto no tienen conocimiento de sus yoes "empíricos", el principio de imparcialidad sería elegido y considerado una necesidad. El problema de la teoría es que el principio exige que las partes que se encuentran en el esfuerzo cooperativo consideren iguales, al menos en sus características relevantes, a sus pares. Fuera de la posición original, en el mundo real, existen ideas del bien que contradicen esta creencia y que de hecho existen en las sociedades liberales.

Dicho esto un segundo mecanismo con el que Rawls fundamenta la estabilidad de la justicia como imparcialidad en Teoría de la Justicia es la psicología moral. Cabe decir que si este argumento funciona, me parece, sería posible sostener el argumento anterior (el de la imparcialidad) pues, de hecho, los ciudadanos se considerarían iguales con el 
La justicia como imparcialidad, progreso y perfección

Diego Alejandro Otero Angelini

paso del tiempo; el problema es que el argumento desde la psicología moral es incorrecto. Rawls reconoce la necesidad de que la concepción de la justicia sea compartida por todos para garantizar su estabilidad:

Para asegurar la estabilidad los hombres deben de poseer un sentido de la justicia o una preocupación por aquellos que estarían en desventaja por su mala acción, preferiblemente ambos. Cuando estos sentimientos son suficientemente fuertes para imponerse a la tentación de violar las reglas, el esquema justo es estable. (Rawls 1999, 435)

Por su parte, el modo en que las personas desarrollan estos sentimientos y adoptan la concepción de la justicia está plasmado en tres leyes o tendencias de la psicología moral:

1. Dada la existencia de la familia y que ésta es una institución justa en donde los padres aman a sus hijos, los menores reconocen el amor de sus padres y los aman en reciprocidad.

2. Dado que las personas desarrollan la capacidad de tener sentimientos hacia sus iguales, inicialmente del modo que se estipula en la primera ley, y que un ordenamiento social es justo y públicamente reconocido, entonces las personas desarrollan los sentimientos afectivos hacia aquellos que viven en dicho ordenamiento en cuanto los otros cumplen con sus deberes y obligaciones de acuerdo a su posición.

3. Dado que la capacidad de una persona de desarrollar sentimientos hacia sus iguales se ha realizado mediante la formación de lazos como se establece en las primeras dos leyes, y dado que las instituciones sociales son justas y públicamente reconocidas por todos, entonces esta persona adquiere el correspondiente sentido de la justicia pues reconoce que él y aquellos que le importan son beneficiarios de dicha ordenación. (Rawls 1999, 429-430)

Es muy claro que estas leyes de la psicología moral son cuestionables. No es evidente que de hecho se cumplan con el rigor de una ley. ¿En realidad es una ley que los padres amen a los hijos?, ¿verdaderamente la familia es una institución justa? En el contexto de Teoría de la Justicia, si el cumplimiento de estas leyes de la psicología moral es necesario para conseguir una sociedad estable para la concepción de la justicia, considero que la empresa rawlsiana está en severo riesgo.

En cualquier caso, Rawls asume que las leyes de la psicología moral ofrecen una generalización adecuada sobre cómo las personas desarrollan sentimientos morales hacia otros individuos y por las instituciones, además confía en que garantizarían la estabilidad de la justicia como imparcialidad en función de que las personas terminan generando los sentimientos morales apropiados para que la estructura básica se estructure con los principios de la justicia y sean estos los que gobiernen las relaciones de los individuos. Para que esto 
La justicia como imparcialidad, progreso y perfección

Diego Alejandro Otero Angelini

sea correcto tenemos que suponer que la justicia como imparcialidad tiende a ocupar un papel central en las relaciones sociales de la comunidad, más allá de la estructura básica, que es su objeto.

Rawls se equivoca al suponer que el impacto de la concepción de la justicia en la formación de los sentimientos morales es suficiente para convertirse en una de las condiciones de estabilidad por sí misma. Esta idea está desarrollada por Benjamín Barber en su crítica a los problemas de justificación en Rawls:

Rawls es incapaz de citar evidencia psicológica o histórica que sugiera que la tolerancia del intolerante lo vuelve más tolerante y consciente de la libertad. El tipo de datos exigidos por aquellos interesados en la evidencia indican que el intolerante está, en la mayor parte, más allá de la racionalidad y por tanto es incapaz de comprender lo que está de fondo en la misma idea de la tolerancia. El intolerante normalmente se refiere a superiores imaginarios con la misma falta de racionalidad con la que tiranizan a sus inferiores imaginarios. Los creyentes fanáticos continuamente parecen comprender la tolerancia por los demás más como un halago que como una reprimenda a su intolerancia. Sin embargo, no debemos falsificar la intención de Rawls para dejar en claro que, en la falta de una sociología política, no sólo se mantiene sin probar sino, igualmente, sin siquiera examinar. (Barber 1975, 671)

La necesidad social de desarrollar legislación contra la discriminación en el mundo es una consecuencia clara de este hecho. Como retomaré en la conclusión, no veo claro hasta qué punto Rawls ofrece herramientas para detener actos de discriminación si no se justifican en términos distributivos y no por los problemas de estabilidad que pueden generar para la sociedad liberal; este punto lo analiza directamente Rawls en Justicia como imparcialidad, una reformulación. El análisis del problema del racismo desde la perspectiva de la justicia como imparcialidad conduce a pensar esos problemas sociales como cualquier otra situación de desventaja en relación a los bienes primarios (Rawls 2001, 65). Es probablemente por la insistencia de Rawls de plantear la justicia como imparcialidad en el contexto de una teoría ideal que no reconoce la relevancia de la discriminación (racial o de género, por ejemplo) como un problema que afecta la estabilidad de la comunidad que no puede ser asimilado a la distribución de bienes primarios. Dada la precaución de Rawls frente a un gobierno que intervenga en el desarrollo del plan de vida de los ciudadanos, la justicia como imparcialidad permite que existan los espacios para que la conducta antiliberal pueda existir. Este es un efecto no deseado del antiperfeccionismo rawlsiano que en el largo plazo pone en riesgo la estabilidad de la concepción de la justicia.

El liberalismo es más que una mera organización política y acuerdos constitucionales y aceptar la concepción no es algo espontáneo; implica un proyecto de vida aun cuando sea uno más o menos indeterminado. En palabras de Brian Barry:

El liberalismo descansa en una visión de la vida: una visión fáustica. Exalta la autoexpresión, el autocontrol y el control sobre el ambiente natural y social; la activa búsqueda del

Revista de Humanidades de Valparaíso, 2020, No 15, 21-40

(c) $(1)(9)$ CC BY-NC-ND 
La justicia como imparcialidad, progreso y perfección

Diego Alejandro Otero Angelini

conocimiento y el choque de ideas; la aceptación de la responsabilidad personal por las decisiones que moldean nuestras vidas. Para aquellos que no pueden con la libertad provee alcohol, tranquilizantes, lucha libre en la televisión, astrología, psicoanálisis y demás sin fin, pero no puede por su naturaleza proveer de ciertas seguridades psicológicas. Como cualquier credo no puede ser justificado o condenado en términos ajenos a él. Es él mismo una respuesta a la pregunta insoluble pero inescapable: ‘¿Cuál es el significado de la vida?’. (Barry 1973, 127)

Lo que vale la pena agregar es que, frente al resto de los credos y concepciones de la justicia existentes, el liberalismo permite a una mayor diversidad de ideas del bien existir bajo su concepción de lo justo. Sin embargo, como todos los credos y concepciones de la justicia, es incompatible con algunas ideas del bien; cuando es incompatible, no parece ser capaz de estructurarse de modo estable, si para eso es necesario que los individuos lo acepten "originalmente". Como afirmaba John Dewey:

No podemos continuar con la idea de que la naturaleza humana, cuando la dejamos sola, cuando está libre de restricciones arbitrarias, tenderá a producir instituciones democráticas que funcionan exitosamente. [...] Debemos reconocer que la democracia significa la creencia en que la cultura humanística debe prevalecer; debemos ser francos y abiertos en el reconocimiento de que nuestra proposición es una moral - como toda idea que se relacione con lo que debería de ser. (Dewey 1989, 97)

Esto significa que no puede existir una concepción de la justicia que reconozca la validez de todas las ideas del bien pues, en último término, eso significaría que no tiene una postura sobre el bien en lo absoluto (aunque no afirmo que Rawls suponga esto). La expectativa rawlsiana de desarrollar un liberalismo antiperfeccionista, que no suponga una idea (o al menos una familia de ideas) del bien, es contraria al hecho de que hay en el liberalismo (o en los liberalismos si se quiere) ciertos ideales de vida en cierto sentido arquetípicos (sin importar que por su naturaleza se puedan materializar de muy diversos modos) que suponen una comprensión moral del liberalismo y son irrenunciables porque, de no existir, la estabilidad de la sociedad liberal estaría comprometida.

Como muestro a continuación, la actitud perfeccionista pragmatista de John Dewey le permitiría a Rawls garantizar las condiciones de estabilidad que él simplemente no ofrece. Esto es así porque cierta concepción del perfeccionismo implica el reconocimiento de bienes liberales que permiten orientar la acción política de modo que tiendan a una sociedad más estable. De igual modo, como es bien sabido, el proyecto deweyano es fundamentalmente un proyecto educativo, lo que conseguiría que la concepción fuera parte de un consenso lo suficientemente amplio como para permitir una sociedad más estable. 
La justicia como imparcialidad, progreso y perfección

Diego Alejandro Otero Angelini

\section{Los fines de la sociedad liberal}

No hay duda de que las sociedades no liberales han tendido a promover una idea de progreso o perfección desde una doctrina comprehensiva particular de modo autoritario. El liberalismo filosófico surgió como una respuesta a las exigencias de sociedades cada vez más plurales, donde el conflicto se fue acrecentando en la búsqueda de la hegemonía política. Sin embargo, aun cuando imponer un ideal de perfección social puede implicar una imposición ilegítima sobre las personas, desde la perspectiva de la sociedad liberal dicho ideal perfeccionista es irrenunciable ya que el liberalismo mismo, contra lo que Rawls planteó en el Liberalismo Político (Rawls 2005, 140), supone una familia de ideas del bien (aquellas que no estén en oposición a los valores liberales) que permiten evaluar la sociedad en términos de desarrollo.

El reto de plantear el ideal perfeccionista en una sociedad liberal es grande. En el momento en que buscamos dar contenido a la idea de la perfección nos encontramos con la posibilidad de convertirnos en aquello a lo que Rawls y la tradición liberal se oponen (la imposición de una visión comprehensiva de la sociedad ilegítima). Sin embargo, una lectura pragmática de la justicia como imparcialidad supondría un ideal de progreso compatible con la concepción de la justicia liberal. En este sentido John Dewey afirma que:

El liberalismo está comprometido con un fin que es al mismo tiempo duradero y flexible: la liberación de los individuos para que la realización de sus capacidades pueda ser la ley de su vida. Está comprometido con el uso libre de la inteligencia como método para dirigir el cambio. (Dewey 2009, 61)

La objeción de orden rawlsiano a la democracia liberal de Dewey podría considerar que es incompatible, y de hecho de un espíritu completamente contrario, con un liberalismo que reconozca el papel de la imparcialidad en la estructuración y elaboración de la concepción de la justicia; que el liberalismo tenga un fin ulterior a la mera ordenación de la sociedad es una extralimitación de la concepción de la justicia a ámbitos que, según Rawls, no son su objeto (Rawls 2005, 194). Cuando en el Liberalismo Político Rawls lleva a cabo el análisis sobre el bien de la sociedad política, plantea el problema al afirmar que: "la justicia como imparcialidad efectivamente abandona el ideal de comunidad política si por ese ideal se significa una sociedad política unida por una (parcial o completa) doctrina comprehensiva religiosa, filosófica o moral" (Rawls 2005, 201). Dicho eso, Rawls nos permite ver cómo es que los fines religiosos, filosóficos o morales no son fines de la sociedad bien ordenada por la justicia como imparcialidad. Teniendo en mente esto, es extraño cuando, en la página siguiente, afirma que los ciudadanos:

[...] comparten un fin político básico, y que tiene la más alta prioridad: el fin de mantener instituciones justas y de darse justicia los unos a los otros, sin mencionar otros fines que

Revista de Humanidades de Valparaíso, 2020, No 15, 21-40

(c) (i) $(9)-\mathrm{O}$ CC BY-NC-ND 
La justicia como imparcialidad, progreso y perfección

Diego Alejandro Otero Angelini

también deben de compartir y realizar a través de sus acuerdos políticos. Además, el fin de la justicia política puede estar entre los fines básicos de los ciudadanos en referencia al cual expresan el tipo de persona que quieren ser.

Junto con otras presunciones, estos fines últimos proveen las bases para el bien de una sociedad bien ordenada. (Rawls 2005, 202)

Es confuso pensar en qué tipo de bienes u objetivos políticos son aquellos que sirven como base para la sociedad bien ordenada, además de estar en referencia al tipo de persona que los ciudadanos quieran ser, sin ser parte de una concepción, al menos parcial, de la moral liberal. El problema, sin embargo, de definir bienes al modo en que lo hace Rawls en el Liberalismo Político es que, aun con los límites del giro político, difícilmente puede justificarlos distanciándose de una comprensión moral de la justicia como imparcialidad:

Con estos asuntos asumidos, la sociedad bien ordenada de justicia como imparcialidad es buena en dos modos. El primero es como un bien para las personas individualmente, y esto por dos razones. Una es que el ejercicio de los dos poderes morales se experimenta como un bien. Esto es una consecuencia de la psicología moral usada en la justicia como imparcialidad. Y que este ejercicio puede ser un bien importante, y lo será para muchas personas, es claro por el papel central de estos poderes en la concepción política de los ciudadanos como personas $[\ldots]$

Una segunda razón por la que la sociedad política es un bien para los ciudadanos es que asegura para ellos el bien de la justicia y las bases sociales para el respeto mutuo. (Rawls, 2005, 202-203)

La idea de que Rawls puede justificar los bienes en su concepción política del ciudadano es un error. Por ejemplo, cuando habla de la psicología moral en el pasaje recién citado, Rawls hace un comentario, en una nota al pie, en el que habla de cómo esa psicología usa el principio aristotélico, planteado en Teoría de la Justicia (Rawls 1999, 372-380). Dicho principio no está distanciado de una doctrina comprehensiva. Lo que es más, cuando afirma que el ejercicio de dicha psicología, no fundada en un argumento político, es un bien, no tiene realmente razones políticas para hacerlo. La idea de que el ejercicio de los poderes morales es un bien está vinculada a un principio liberal y moral de autonomía que Rawls carga de contrabando al argumento.

La afirmación de los poderes morales de los individuos implica una comprensión de la razón perteneciente a una familia de doctrinas comprehensivas, herederas en buena medida de la modernidad. El ejercicio y desarrollo de la inteligencia es una labor social en la medida en que nuestra naturaleza así nos condiciona, necesitamos de la sociedad para desarrollarla (Dewey 2007, 762); la sociedad liberal, dicho esto, está en condición de promover y facilitar el uso de la inteligencia o, por otro lado, podría abdicar a esta presunta responsabilidad. Suponiendo que garantizar la libertad en su justo valor, para lo que es necesario permitir y promover el ejercicio de los poderes morales, sea uno de los fines 
del liberalismo, el progreso (consecuencia del uso de la inteligencia a la solución de los problemas), y un tipo de perfeccionismo pragmático, sería una de las consecuencias de la aplicación de una concepción liberal de la justicia (Dewey 1998, 84-90).

Si reconocemos estos presupuestos, la relación entre liberalismo y progreso parece ser necesaria. En la medida en que los individuos gocen en su vida ordinaria de cierta libertad, tenderán a generar progreso en un sentido pragmatista deweyano (Dewey 2009, 63). Este concepto de perfección no plantea un objetivo último al que el ser humano deba acceder. Por el contrario, asume que dadas las condiciones adecuadas, los individuos serán capaces de generar nuevos estándares a los que puedan acceder en función a sus circunstancias específicas. Es decir, el objetivo de Dewey es plantear un tipo de perfeccionismo que entienda que no es necesario plantear una meta final, una escala última, sino con la capacidad de resolver los problemas a los que uno se enfrente en el momento (Dewey1998, 85). Ahora bien, una objeción podría ser que esta idea de perfección, al no apuntar a un fin concreto, es que es un concepto inútil (pues no quedaría claro hasta qué punto podríamos plantear fines y circunstancias sociales a partir de él), pero esto sería pasar por algo que en la idea de perfeccionamiento deweyano son los individuos, cada una de las personas, las que deben de ser capaces de "perfeccionarse" según el estándar que ellos indaguen. Esto significa que, aun cuando la sociedad no busque una igualdad en los fines que deben perseguir las personas (o en los resultados que obtengan de sus indagaciones personales), si debe de generar una igualdad de condiciones para que cada persona pueda perseguir su perfección: bienes primarios como los marca la justicia como imparcialidad, pero también una cultura que promueva el desarrollo individual, la libertad, la igualdad moral y la autonomía; todos esos valores comprehensivos de las sociedades liberales.

De este modo, la sociedad más avanzada, al menos desde un proyecto civilizatorio liberal, no es una en la que todos se comporten igual por la coacción de un agente externo a ellos, sino aquella que permita que todos los proyectos de vida o comprensiones del bien compatibles con la concepción de la justicia liberal sean "puestos a prueba" y se encuentren abiertos a la crítica y evaluación; una sociedad de individuos libres, iguales, autónomos que puedan construir sus propios proyectos de vida e indaguen el modo de alcanzarlo según su propio parecer.

En una sociedad liberal que tiende al progreso en términos deweyanos se puede limitar el pluralismo, a veces mediante la elección libre de ciudadanos que prefieren otros proyectos de vida y, cuando genere riesgos a la estabilidad, ponga en riesgo las libertades de otros individuos o incluso, sin ser un riesgo eminente, promueva una visión contraria a la concepción liberal, puede hacerse mediante la censura (o algún otro mecanismo de exclusión comparable) legítima. Un ejemplo de una concepción de la sociedad liberal así está expuesto por Jeremy Waldron, quien defiende la importancia de pensar los límites a la libertad de expresión más allá del principio del daño (elaborado por Mill), enfocándose en particular en el discurso de odio (Waldron 2014). Waldron asume, en contra de las aparentes consecuencias del liberalismo antiperfeccionista, que algunos modos de expresión 
atentan contra valores públicos fundamentales, como puede ser la igual dignidad de los miembros de la comunidad, y eso puede ser razón suficiente para moderar o censurar su presencia en el espacio público.

Aun cuando el análisis y la crítica a la propuesta de Waldron ameritaría mayor detenimiento, considero que la defensa de ciertos valores públicos, como la no discriminación por razones de raza, sexo o religión (aun cuando no tenga un impacto directo en la distribución de bienes primarios), es compatible con el progresismo liberal de Dewey, que no está definido por un estilo de vida particular o un tipo de modelo final (lo que considero que es la gran preocupación de Rawls respecto del perfeccionismo) (Dewey 2009, 40). El progreso liberal enfocado al ciudadano supone una persona que puede utilizar su razón para definir libremente los proyectos de vida que satisfacen sus necesidades dadas sus condiciones vitales. Este liberalismo conduce al progreso de un modo similar en que la evolución por selección natural lo ha hecho: desechando las opciones inviables, manteniéndose abierto a las posibilidades del futuro (Dewey 1998, 141). El futuro de la sociedad liberal no puede ser definido con precisión, la sociedad liberal se resiste a ser pensada en términos de utopía pues está compuesta por personas que son capaces de pensarse y pensar su mundo de un modo distinto y autónomo dependiendo de sus circunstancias.

Uno de los fines de una sociedad liberal ordenada por la justicia como imparcialidad que reconozca la idea de progreso liberal sería que todas las personas tengan igual oportunidad de ejercer sus poderes morales y el uso de su inteligencia del modo más libre que la sociedad misma ofrezca. Para poder permitir este desarrollo de poderes morales y de inteligencia debe, al mismo tiempo, ser capaz de enfrentar el conflicto de un modo productivo generando progreso y perfeccionamiento en un sentido pragmático.

\section{Consecuencias educativas del perfeccionismo}

Para finalizar quisiera plantear algunas de las consecuencias del reconocimiento del progresismo y perfeccionismo social que planteé en el ámbito educativo. Como ya lo expuse, el tipo de perfeccionamiento del que estoy hablando se fundamenta en la idea de desarrollo continuo cuasi evolutivo en el que los individuos plantean sus propios estándares en función de la situación en la que se encuentran. El hecho que la sociedad apunte al perfeccionamiento de sí mediante el desarrollo de sus ciudadanos implica que éstos serán capaces de comprender los estándares que dictaminan la acción en los distintos ámbitos de su sociedad (es decir que podrán evaluar críticamente las acciones y sus principios) y, al hacerlo, estarán en condición de afirmarlos o superarlos dependiendo de sus circunstancias: "El estándar siempre es reformulado con base en la experiencia presente aunque formulado con base en la experiencia pasada" (Dewey 1998, 87). Siempre que los miembros de la sociedad puedan actuar de este modo, el progreso y el perfeccionamiento 
La justicia como imparcialidad, progreso y perfección

Diego Alejandro Otero Angelini

de la sociedad deberá ser la consecuencia. Lo que podríamos anticipar es que, en una sociedad abierta al pensamiento crítico, los ciudadanos se mantienen abiertos al diálogo y la discusión pública.

Para alcanzar una sociedad estable, en donde los ciudadanos son parte del consenso traslapado y, además, la sociedad contribuye al ejercicio de los poderes morales de los ciudadanos, es necesario reconsiderar los límites al espacio privado. Esto es porque la búsqueda de las condiciones para la operación de los conceptos de progreso y perfección dependen de generar circunstancias adecuadas para que todos los ciudadanos posean libertad y autonomía suficiente y esto, necesariamente, tiene implicaciones en el modo en que el bien público se relaciona con la privacidad de los individuos. El campo de la educación, especialmente dentro del núcleo familiar, es uno de esos ámbitos en que los límites entre lo público y lo privado deben de ser continuamente pensados.

No me parece controversial aceptar que la educación familiar, en las sociedades democráticas, ha tendido a generar oportunidades distintas entre los individuos; el mismo Rawls reconoce que la familia es una de las primeras causas de desigualdad (Rawls 1999, 64). La construcción de una sociedad gobernada por la justicia como imparcialidad no puede dejar de lado a los futuros ciudadanos en un momento y en un espacio tan fundamental para su desarrollo como es la familia, entendida como fuente del bien primario de la educación en una sociedad democrática que valora la libertad. Aun cuando la justicia como imparcialidad busque, como afirmó Rawls en Liberalismo Político, generar condiciones en las que "[...] aquellos que se quieran retirar del mundo moderno de acuerdo a los contenidos de su religión siempre que acepten los principios de la concepción política de la justicia y aprecien sus ideales políticos de la persona y la sociedad" (Rawls 2005, 200), los menores de edad no están en condiciones de hacer una elección tan importante en sus vidas (como retirarse a vivir una vida fuera de la formación y de los logros que el mundo moderno ha conseguido... como es la aceptación de todos los individuos como libres e iguales por ejemplo).

Supongamos que un ciudadano decide convertirse a un culto religioso donde no se le trate con igualdad y no se respete su autonomía en lo privado, aunque no puedan hacer eso en "lo público", porque así se encarna su idea del bien particular; en un caso así la justicia como imparcialidad, e incluso la idea de perfeccionamiento de Dewey, tendría que respetar esa decisión (aunque considero que si estamos hablando de una persona plenamente consciente de su igualdad, libertad y que vive y decide autónomamente la probabilidad es que esto ocurra esporádicamente). Sin embargo, para hacer que esa decisión sea aceptable, la persona que la toma debe haber estado en una posición en que pueda decidir libre y autónomamente en un principio.

Un mecanismo común para garantizar esas condiciones de libertad y autonomía en las sociedades democráticas y liberales contemporáneas han sido los sistemas educativos

Revista de Humanidades de Valparaíso, 2020, No 15, 21-40

(c) $(9)(9)$ CC BY-NC-ND 
La justicia como imparcialidad, progreso y perfección

Diego Alejandro Otero Angelini

escolarizados. Con esto en mente, terminaré con una breve reflexión sobre este modo de educación para poder generar condiciones de estabilidad para la justicia como imparcialidad.

\section{Conclusiones: educación para la estabilidad de una sociedad liberal}

El debate sobre la educación en las sociedades democráticas tiene múltiples aristas. Por ejemplo, es posible discutir si la sociedad debería permitir la educación privada además de la pública o si sólo debería ser el Estado el encargado de impartir educación. Otro debate podría ser si los padres deberían elegir dónde asisten a la escuela sus hijos, si es mejor una escuela mixta o sólo para un género en especial. También está abierto a debate si los padres deberían de participar en las actividades escolares y, si sí, cuánto. La relevancia de todas esas discusiones es, sin embargo, secundaria en la medida en que no tengamos una comprensión correcta de cuáles son los fines de la educación, al menos en relación a su contribución a la estabilidad de la sociedad (entendiendo que tiene más fines que sólo contribuir a la estabilidad de la concepción de la justicia).

Dentro de la justicia como imparcialidad la educación es tratada como un bien primario en la medida en que permite la obtención de oportunidades y recursos para los ciudadanos. No deja de ser curioso, sin embargo, que las reflexiones sobre la educación, tanto en Teoría de la Justicia como en el Liberalismo Político son pocas. En su primera gran obra Rawls trata la cuestión de los siguientes modos:

1. "[...] el valor de la educación no debe de ser considerado únicamente en términos de su eficiencia económica y bienestar social. Igualmente, si no es que más importante, es el papel de la educación de permitir a la persona disfrutar de la cultura si su sociedad toma parte en ella; de este modo debe proveer para cada individuos un sentido seguro de su propio valor" (Rawls1999, 87).

2. "[...] los recursos para la educación no deben de ser designados sólo o principalmente de acuerdo a su retorno estimado en habilidades productivas desarrolladas, sino de acuerdo a su valor en el enriquecimiento personal y de la vida social de los ciudadanos, incluyendo aquí a los menos favorecidos" (Rawls 1999, 92).

3. "Por tanto, la educación moral es una educación para la autonomía. En su debido tiempo todos sabrán por qué elegirán los principios de la justicia y cómo se derivan de las condiciones que caracterizan su situación de personas morales iguales en una sociedad. De esto se sigue que al aceptar esos principios no se hace en base a la tradición principalmente o la opinión de los demás" (Rawls 1999, 542).

Como se puede ver en Teoría de la Justicia, antes del "giro político", Rawls reconocía en la educación un fin civilizatorio que propicia el desarrollo de individuos autónomos para que formen parte de un consenso fuerte sobre la concepción de la justicia. Esta

Revista de Humanidades de Valparaíso, 2020, No 15, 21-40

(c) $(9)(9)$ CC BY-NC-ND 
La justicia como imparcialidad, progreso y perfección

Diego Alejandro Otero Angelini

concepción de la educación es compatible con la finalidad de la sociedad liberal que se perfila como una que promueva cierto perfeccionismo, uno al modo que he expuesto en la sección anterior. Ahora bien, con el giro político Rawls reconsideró los límites de la educación de un modo incompatible con la idea de perfeccionamiento que he tratado hasta ahora y que no genera las condiciones de estabilidad para las que la educación podría contribuir:

Más allá de los requisitos ya descritos, la justicia como imparcialidad no busca cultivar las virtudes y valores distintivos del liberalismo de la autonomía y la individualidad, o de cualquier otra doctrina comprehensiva. [...] Vale la pena reconocer aquí que intentamos responder la cuestión sobre la educación de los niños completamente dentro de la concepción política. La preocupación de la sociedad con su educación descansa en su papel como futuros ciudadanos, y esto implica cosas esenciales como que adquieran la capacidad de comprender la cultura pública y que participen de sus instituciones, que sean económicamente independientes y se puedan mantener por sí solos durante toda una vida, que desarrollen las virtudes políticas, todo esto desde un punto de vista político. (Rawls 2005, 199-200)

Esta comprensión de la educación, posterior al giro político, no reconoce la relevancia de la educación en la formación de una sociedad común y, al mismo tiempo, de cómo los individuos de hecho construyen su psicología moral (como ya he tratado con cierta amplitud). John Dewey nos permite comprender una faceta de la educación en la vida de las sociedades que trasciende los límites de Liberalismo Político y que nos acerca un poco más, al menos en sus fines, a Teoría de la Justicia:

La sociedad existe a través de un proceso de transmisión similar al de la vida biológica. Esta transmisión ocurre por medio de los hábitos de comunicación de la acción, el pensamiento y el sentir de los más viejos a los más jóvenes. Sin la comunicación de ideales, esperanzas, expectativas, estándares y opiniones de aquellos miembros de la sociedad que están saliendo del grupo a aquellos que están entrando, la vida social no podría existir. Si los miembros que componen a una sociedad vivieran continuamente, podrían educar a los nuevos miembros que llegaran, pero sería una tarea dirigida por el interés personal más que una necesidad social. Ahora es el trabajo de la necesidad.

[...] Las diferencias en edades, el hecho de que algunos nacen y otros mueren, hace posible mediante la transmisión de ideas y prácticas la renovación del fundamento social. Sin embargo esta renovación no es automática. A menos que se lleven a cabo trabajos para que exista una genuina transmisión, el grupo más civilizado recaerá en el barbarismo y después en el salvajismo. (Dewey 2013, 14-15)

El gobierno no hace suficiente con garantizar una educación técnica y política para los ciudadanos y menores de edad. En la medida en que la concepción de la justicia debe ser estable para que cumpla sus objetivos, se vuelve una necesidad de vital importancia el de-

Revista de Humanidades de Valparaíso, 2020, No 15, 21-40

(c) $(1)(9)$ CC BY-NC-ND 
La justicia como imparcialidad, progreso y perfección

Diego Alejandro Otero Angelini

sarrollo de proyectos educativos que promuevan el credo liberal (de tolerancia, igualdad, respeto e inclusión) pues, de lo contrario, la sociedad "recaerá en el barbarismo y después en el salvajismo". Esos valores liberales son, sin duda, morales.

Las contribuciones de Amy Gutmann en este punto son un referente. Para ella la dependencia de las sociedades a la existencia de ciudadanos y sus decisiones morales convencidos de la conveniencia de la democracia, conduce a que el gobierno deba tener un cierto control, al menos, sobre el currículo (Gutmann 1999, 49). Esto es claro cuando critica la posición rawlsiana por insuficiente:

Rawls puede estar en lo correcto sobre lo natural que es aprender la moralidad de los principios en una sociedad justa. Pero la autonomía sin duda no viene naturalmente en una sociedad menos que justa. Esa ahí donde parece ser más necesario. Si nuestras escuelas pueden desarrollar en los niños la moralidad de los principios, generarían ciudadanos comprometidos a extender la justicia frente a la injusticia, una meta mucho más necesaria en una sociedad injusta que en una justa. (Gutmann 1999, 59)

Como ya intenté mostrar, creo que Amy Gutmann estaría siendo excesivamente generosa con Rawls abriendo la puerta a que la moralidad se aprenda del modo en que supone en una sociedad justa; lo que es claro, y comparto totalmente con la filósofa, es que en una sociedad menos que justa no hay condiciones para garantizar que la moralidad "correcta" (una moralidad liberal de respeto a las libertades, la igualdad y que promueva la autonomía) sea aprendida por los menores. Por tanto, asumiendo que la sociedad bien ordenada es fundamentalmente una idealización de las sociedades reales, parcialmente ordenadas, la formación que podría recibir un menor en bajo un esquema de liberalismo político como el que Rawls delinea en Liberalismo Político no sería adecuado para desarrollar ciudadanos auténticamente libres (no sólo formalmente). Por el contrario, un esquema liberal comprehensivo, como parecía que Rawls consideraba al menos parcialmente en Teoría de la Justica y que encontraríamos en una sociedad que se fuera compatible con el ideal de progreso deweyano, presenta ventajas que parecerían ser evidentes:

Con certeza los liberales comprehensivos comparten razones basadas en la legitimidad del estado de apoyar la individualidad y la autonomía que no están disponibles para los liberales políticos. Estas razones podrían explicar los esfuerzos del Estado de enseñar a los niños sobre culturas diversas incluso en sociedades no democráticas que no tienen la oportunidad de ser democráticas. Enseñar a los niños a comprender y evaluar otros modos de vida puede ser públicamente valorado como una manera de cultivar individualidad, distintas de sus contribuciones a la educación democrática—política podríamos decir. (Gutmann 1995, 564)

La escuela, desde esta lógica, debe funcionar para desarrollar ciudadanos capaces de vivir su vida autónomamente de modo que puedan enfrentar la vida de modo inteligente.

Revista de Humanidades de Valparaíso, 2020, No 15, 21-40

(c) $(1) \Theta(-)$ CC BY-NC-ND 
Este es el ideal perfeccionista que Dewey defendería para la escuela. Si vamos a vivir en sociedades democráticas y libres, gobernadas por una concepción de la justicia como la justicia como imparcialidad, entonces es necesario garantizar las condiciones necesarias para la libertad. Las sociedades democráticas no se mantienen por sí solas y la búsqueda de condiciones que permitan el desarrollo de ciudadanos aptos para vivir en ellas implica una postura que promueva una visión del ser humano como uno capaz de reconocer en los demás a sus iguales, con derecho a ser libres, a poder vivir su vida como prefieran y que los prepare para, de hecho, poder hacerlo. Esto puede ser incluido en las funciones que Dewey previó para las escuelas:

1. Transmitir los avances de la civilización.

2. Eliminar del ambiente social algunas de sus características que promueven actitudes incorrectas. Ayudando a los menores a poner en duda las creencias que obstaculizan su desarrollo como ciudadanos democráticos.

3. Por último las escuelas deben de dar oportunidad a todos los individuos, independientemente del grupo social al que pertenezcan, de conseguir una oportunidad para educarse adecuadamente. (Dewey 2013, 22-23)

En último término me parece que el repensar la justicia como imparcialidad como una concepción de la justicia compatible con un ideal de perfección y progreso particular, el ideal pragmatista de Dewey, no vulnera sus intenciones plenamente liberales: las de promover un sistema de cooperación en el que los individuos puedan elegir el modo en que cooperarán con los demás. Al mismo tiempo, retomar el ideal de progreso y perfección pragmáticos de Dewey ayuda a orientar algunas de las instituciones fundamentales de modo que se generen mejores condiciones de estabilidad en el futuro.

El ideal deweyano de perfección es el de desarrollar una cultura democrática donde, a causa de la autonomía de cada uno de los individuos, cada persona se convierta en una especie de investigador sobre qué es lo que prefiere y la manera en que puede conseguirlo para su vida. Sin un fin similar a ese, la posibilidad de que los futuros ciudadanos (asumiendo que los presentes forman parte del consenso traslapado que pretende Rawls) adopten la concepción de la justicia es dejada a la suerte; esa no es una condición aceptable para una concepción de la justicia. Educar a los ciudadanos del futuro implica enseñarles a pensar por sí mismos, a ser autónomos: "Enseñar a los niños a pensar sobre la justicia social implica enseñarles que puede ser razonable estar en desacuerdo con sus padres y sus maestros - y cualquier otra autoridad - en temas políticos relevantes" (Gutmann 1995, 578). Al final, educar para la democracia significa educar para buscar el progreso en los términos en que cada uno los pueda y quiera establecer dentro de los márgenes de una concepción de la justicia adecuada. 
La justicia como imparcialidad, progreso y perfección

Diego Alejandro Otero Angelini

\section{Referencias bibliográficas}

Barber, Benjamin (1975). Justifying Justice: Problems of Psychology, Measurement, and Politics in Rawls. The American Political Science Review, 69(2): 663-674. doi: https://doi. org/10.2307/1959095

Barry, Brian (1973). The Liberal Theory of Justice. Londres: Oxford University Press.

Dewey, John (1989). Freedom and Culture. Nueva York: Prometheus Books.

Dewey, John (1998). Principles of Instrumental Logic. Carbondale: Southern Illinois University Press.

Dewey, John (2007). Logic. Nueva York: Saerchinger Press.

Dewey, John (2009). Liberalism and Social Action. Reno: Frederick Ellis.

Dewey, John (2013). Democracy and Education. Dehli: Aakar.

Gutmann, Amy (1995). Civic Education and Social Diversity. Ethics, 105(3): 557-579.

Gutmann, Amy (1999). Democratic Education. Princeton: Princeton University Press.

Rawls, John (1999). A Theory of Justice. Cambridge: Harvard University Press.

Rawls, John (2001). Justice as Fairness, a restatement. Erin Kelly (ed.). Cambridge: Harvard University Press.

Rawls, John (2005). Political Liberalism. Nueva York: Columbia University Press.

Waldron, Jeremy (2014). The Harm in Hate Speech. Cambridge: Harvard University Press.

Wolin, Sheldon (2016). The Liberal/Democratic Divide: On Rawls's Political Liberalism. En Sheldon Wolin, Fugitive Democracy and other essays, pp. 260-280. Princeton: Princeton University Press. 